Л. Д. Мисник, к.т.н., доцент

e-mail: 1.mysnyk@chdtu.edu.ua

Черкаський державний технологічний університет

б-р Шевченка, 460, м. Черкаси, 18006, Україна

\title{
УПРАВЛІННЯ ФОРМУВАННЯМ ТА РЕАЛІЗАЦІЕЮ ПІДГОТОВКИ І ПРОВЕДЕННЯ КОНТРОЛЮ ЗНАНЬ ПРИ ДИСТАНЦІЙНОМУ НАВЧАННІ СТУДЕНТІВ
}

Стаття присвячена пошуку нових форм та методів навчання, вдосконаленню тестових технологій з метою їх відповідності європейським вимогам та можливості управління формуванням та реалізацією підготовки і проведення контролю знань при дистаниійному навчанні. Представлено метод управління тестовими технологіями, що реалізується через функиії організачії, планування і моніторингу. Запропонований метод базується на відображенні прочесів управління в дводольних графах з подальшим розрахунком моделі реалізації дій шляхом слідування активності між статичними та динамічними елементами цих технологій.

Ключові слова: дистанційні технології навчання, методи управління інформаційними технологіями, тестові технології та контроль знань.

Постановка проблеми. Третє тисячоліття ставить перед нашою країною нові завдання і вимагає пошуку шляхів для їх вирішення. Одним із таких завдань $є$ інтеграція України у світову економіку, що неможливо без спеціалістів з високим рівнем кваліфікації. Особлива роль у цьому процесі належить вищим навчальним закладам. В умовах науковотехнічного прогресу підвищуються вимоги до спеціалістів, якості їх знань, навиків і вмінь, здатності ефективно працювати в умовах світової інтеграції. Для здійснення цього традиційними засобами необхідні значні затрати на закордонні відрядження, організацію міжнародних зустрічей та конференцій, запрошення іноземних викладачів, що за нинішньої соціально-економічної ситуації в Україні є досить проблематичним. Вирішувати цю проблему значною мірою покликані сучасні інформаційні та телекомунікаційні технології, технології дистанційного навчання.

Аналіз останніх досліджень і публікацій. Останнім часом виконано чимало досліджень щодо проблеми впровадження дистанційних технологій у навчальний процес навчальних закладів різних типів, зокрема, наукове забезпечення дистанційної професійної освіти, проблеми та напрями досліджень (В. Биков, М. Михальченко, Л. Лещенко, П. Стефаненко) [1-3]; теоретико-методологічні основи дистанційної освіти (В. Олійник, В. Жулкевська, Н. Жевакіна, М. Танась, П. Таланчук, та ін.) [4-6]; психолого-педаго- гічні аспекти і технології створення дистанційного курсу (В. Кухаренко, Т. Олійник, О. Рибалко, Н. Сиротенко, А. Петренко, М. Бесєдіна та ін.) [7]; можливості й перспективи дистанційного навчання у вищих навчальних закладах України та за кордоном, створення електронних навчальних курсів та електронних тестів (Р. Гуревич, В. Жулькевська, П. Стефаненко, В. Вишнівський та ін.) [8, 9].

Однак деякі аспекти впровадження технологій дистанційного навчання, зокрема ті, що стосуються управління формуванням i реалізацією підготовки та проведення контролю знань при дистанційному навчанні, потребують доопрацювання.

Мета роботи - розробка методу управління формуванням та реалізацією підготовки і проведення контролю знань, що дасть змогу швидко і оперативно адаптувати процеси дистанційного навчання до рівня знань студентів, забезпечити формування повної, достовірної, своєчасної інформації про хід засвоєння знань. Це актуально і в зв'язку з потребою розробки навчально-методичного забезпечення підготовки фахівців за цією системою, зокрема тестів та навчального матеріалу.

Основний матеріал досліджень. Досвід застосування інформаційних технологій свідчить про необхідність створення систем тестування на базі деякого інструментального програмного середовища 3 нарощуванням навколо нього інших функціональних і забезпечуючих компонентів. За такий базис пропо- 
нується взяти модульне об'єктно-орієнтоване динамічне навчальне середовище - Moodle (Modular Object-Oriented Dynamic Learning Environment). Це безкоштовна веб-платформа дистанційного навчання 3 відкритим кодом, основи якої були закладені в 90-х роках Мартіном Доуджіамосом (Martin Dougiamas, Австралія). 3 того часу зусиллями великої кількості фахівців з усього світу цей проект пройшов значний шлях розвитку, і продовжує інтенсивно розвиватися і сьогодні [10].

B результаті Moodle став найпопулярнішою і найбільш досконалою системою дистанційного навчання у світі, якою на даний момент користуються тисячі користувачів у більш ніж 200 країнах світу. Moodle перекладений понад 70 мовами, включно з українською, і $є$ основною веб-платформою дистанційного навчання, рекомендованою Українським інститутом інформаційних технологій в освіті.

Але система тестування для поточного i підсумкового контролю знань студентів - це не тільки і не скільки програмний комплекс. Це, в першу чергу, чітка організація всіх дій 3 підготовки тестів, організації тестування та проведення тестування студентів. Виділення 3 сукупності наведених задач лише задачі розробки програм тестування i iï вирішення у відриві від наведених, порушує системність вдосконалення навчального процесу. Потрібна цілісна упорядкована система зв'язків наступності між процесами тестової технології, яка забезпечить організацію, планування, проведення і використання результатів тестування [11]. Потрібно управління технологією.

Для управління процесами формування та реалізації підготовки і проведення контролю знань студентів необхідно використати методи планування. В практиці управління для цього найчастіше використовують сітьові моделі. Та для вирішення поставленої задачі краще застосувати моделі, які містять три типи об'єктів: екземпляри інформаційного представлення (сукупність документів, таблиць баз даних, описів та ін., які відображають інформаційне середовище процесу навчання студентів і формуються в процесі тестування студентів), процедури породження нової інформації (сукупність взаємопов'язаних дій, пов'язаних 3 класифікацією, інтеграцією, зіставленням, оцінюванням, виконанням операцій над параметрами екземплярів інформаційних представлень, що поро- джує нову інформацію) та зв'язки між ними. Для моделювання процесів формування інформаційного ресурсу процесу навчання і контролю знань використаємо дводольні графи, які дають змогу відобразити процеси взаємодії трьох типів об’єктів.

Щоб розробити методи управління, які базуються на плануванні процедур породження нової інформації та екземплярів інформаційного представлення, необхідно спочатку створити структуру задач і наповнити ії змістом (табл. 1).

Таблиця 1

Структура задач по підготовці тестів та тестуванню студентів

\begin{tabular}{|l|l|}
\hline № 3/п & \multicolumn{1}{|c|}{ Задача } \\
\hline 1 & $\begin{array}{l}\text { Створення та реалізація } \\
\text { тестових технологій навчання }\end{array}$ \\
\hline 1.1 & Підготовка тестових завдань \\
\hline 1.1 .1 & Організація підготовки \\
\hline 1.1 .2 & Підготовка засобів тестування \\
\hline 1.1 .3 & $\begin{array}{l}\text { Підготовка робочих програм } \\
\text { дисциплін відповідно до умов } \\
\text { реалізації тестових технологій }\end{array}$ \\
\hline 1.1 .4 & Планування розробки тестів \\
\hline 1.1 .5 & Створення тестів \\
\hline 1.1 .6 & $\begin{array}{l}\text { Формування інформаційного } \\
\text { середовища тестування }\end{array}$ \\
\hline 1.1 .7 & Звітування про виконання \\
\hline 1.2 & Тестування студентів \\
\hline 1.2 .1 & Розробка плану тестування \\
\hline 1.2 .2 & $\begin{array}{l}\text { Підготовка студентів } \\
\text { до тестування }\end{array}$ \\
\hline 1.2 .3 & Тестування \\
\hline 1.2 .4 & Обробка результатів тестування \\
\hline 1.2 .5 & $\begin{array}{l}\text { Моніторинг } \\
\text { тестових технологій }\end{array}$ \\
\hline 1.2 .6 & Звітування про виконання плану \\
\hline 1.20
\end{tabular}

Процеси наповнення інформаційного ресурсу при формуванні та реалізації підготовки і проведенні контролю знань студентів представимо через дводольні графи $D$, які містять вершини ( $L$ - ліва підмножина вершин дводольного графа і $P$ - права підмножина) та $Z$ - зв' язки наступності (ребра) в дводольному графі.

Задаємося параметрами вершин та peбер.

Вершини типу $L$ (ліва підмножина вершин графа) - це дії по реалізації чи управлінню тестовою технологією. Вершини типу $P$ 
(права підмножина вершин) - екземпляри інформаційних представлень, які $є$ результатом реалізації дій і являють собою інформаційний ресурс системи навчання і тестового контролю знань.

Зв'язки в такій моделі відображають порядок формування і використання інформації в процесах навчання і тестового контролю знань та задають терміни формування екземплярів інформаційного представлення і початку реалізації дій. Метод полягає у виконанні наступних моментів.

1. Сформованість екземпляра інформаційного представлення оцінюється за максимальним часом завершення дій, які передують цьому формуванню:

$$
t\left(p_{j}\right)=\max _{z\left(l_{i}, p_{j}\right)=1}\left(t\left(l_{j}\right)\right),
$$

де $p_{j} \in P$ - вершина правої підмножини $P$ дводольного графа;

$l_{i} \in L-$ вершина лівої підмножини $L$ дводольного графа;

$t\left(p_{j}\right)$ - момент часу сформованості екземпляра інформаційного представлення, що відповідає вершині $p_{j}$;

$t\left(l_{j}\right)$ - момент часу завершення виконання дій у технології навчання і контролю чи в процесах управління тестовою технологією, що відповідає вершині $l_{i}$;

$z\left(l_{i}, p_{j}\right)-$ функція, що визначає наявність зв'язку (ребра) між вершинами $l_{i}, p_{j}(1-$ зв'язок $\epsilon, 0-$ зв'язку немає).

2. Завершення виконання дій у технології навчання і тестового контролю знань чи в процесах управління технологією визначається за максимальним часом сформованості відповідного екземпляра інформаційного представлення:

$$
t\left(l_{k}\right)=\max _{z\left(p_{s}, l_{k}\right)=1}\left(t\left(p_{s}\right)\right) .
$$

Реалізація методу управління процесами навчання і тестового контролю знань полягає у виконанні наступних дій.

- Створення дводольного графа, ліва підмножина $L$ вершин якого відображає процедури по реалізації технології навчання і тестового контролю знань. Права підмножина $P$ відповідає результатам реалізації цих дій. Ребра дводольного графа означають порядок і умови виконання дій по формуванню елементів процесу.
- Розрахунок планових моментів часу початку виконання дій і формування елементів тестової технології.

Якщо розраховані показники часу виконання окремих підмножин дій влаштовують учасників процесу - затвердження плану.

- Визначення підмножини елементів тестової технології $P^{*}=\left\{p_{k}^{*}\right\}, k=1, N^{*}$, час формування яких не влаштовує учасників тестування.

- Вибір підмножини $P^{* *}=\left\{p_{y}^{* *}\right\}, y=$ $1, N^{* *}$ підмножини $P^{*}$, в якій елементи тестової технології можуть бути сформовані без отримання інших елементів множини:

$$
\begin{gathered}
\forall p_{y}^{* *} \in P^{* *}, p_{l}^{*} \in P^{*}, m, \overline{l_{l_{\jmath}}} \in L, \overline{p_{q_{J}}} \in P^{*}: \\
z\left(p_{y}^{* *}, \overline{l_{l_{1}}}\right) \cdot \prod_{j=1}^{m-1}\left[z\left(\overline{l_{l_{\jmath}}}, \overline{p_{q_{J}}}\right) .\right. \\
\left.z\left(\overline{p_{q_{J}}}, l_{i_{j+1}}\right)\right] \cdot z\left(\overline{l_{l_{m}}}, p_{l}^{*}\right)=0 .
\end{gathered}
$$

- Виконання від дії $l_{i_{1}}$ до дії $l_{i_{m}}$. I коли для всіх шляхів (всіх проміжних продуктів $\left.\forall \overline{p_{q_{j}}} \in P^{*}\right)(m-$ кількість проміжних вершин графа) добуток дорівнює 0, це означає, що шляхів немає.

- Вибір $з$ підмножини $P^{* *}$ того елемента, який формується найраніше:

$p_{z}^{* *} \in P^{* *} \Longrightarrow t\left(p_{y}^{* *}\right) \leq t\left(p_{x}^{* *}\right), x=1, N^{* *}$.

- Знаходження необхідного моменту часу формування елемента тестової технології $p_{Z}^{* *}-t_{0}\left(p_{Z}^{* *}\right)$.

- Внесення змін в дії, які приводять до створення елемента тестової технології $p_{b}^{* *}$ в момент часу, більший ніж $t_{0}\left(p_{z}^{* *}\right)$ :

$$
\forall p_{b}^{* *} \in P^{* *}, t\left(p_{z}^{* *}\right)>t_{0}\left(p_{b}^{* *}\right) .
$$

- Розрахунок нових моментів часу виконання дій і формування елементів тестової технології.

Представлений метод дає змогу створити раціональний план виконання дій в навчальній і тестовій технології, починаючи процес 3 найбільш незалежних елементів технології, та створити систему дистанційного навчання і тестування, що включатиме компоненти, які забезпечать:

- регламентацію (організацію) робіт 3 підготовки тестів і тестування студентів;

- створення тестів та розміщення їх на сторінках навчальних дисциплін;

- автоматичну ідентифікацію і верифікацію осіб, що проходять тестування; 

вання;

• контроль за роботою системи тесту-

- статистичну обробку та відображення результатів тестування;

- моніторинг результатів тестування.
На рис. 1 і 2 показано графи взаємодії в процесах підготовки засобів тестування та розробки тестів як приклади детального виконання задач табл. 1.

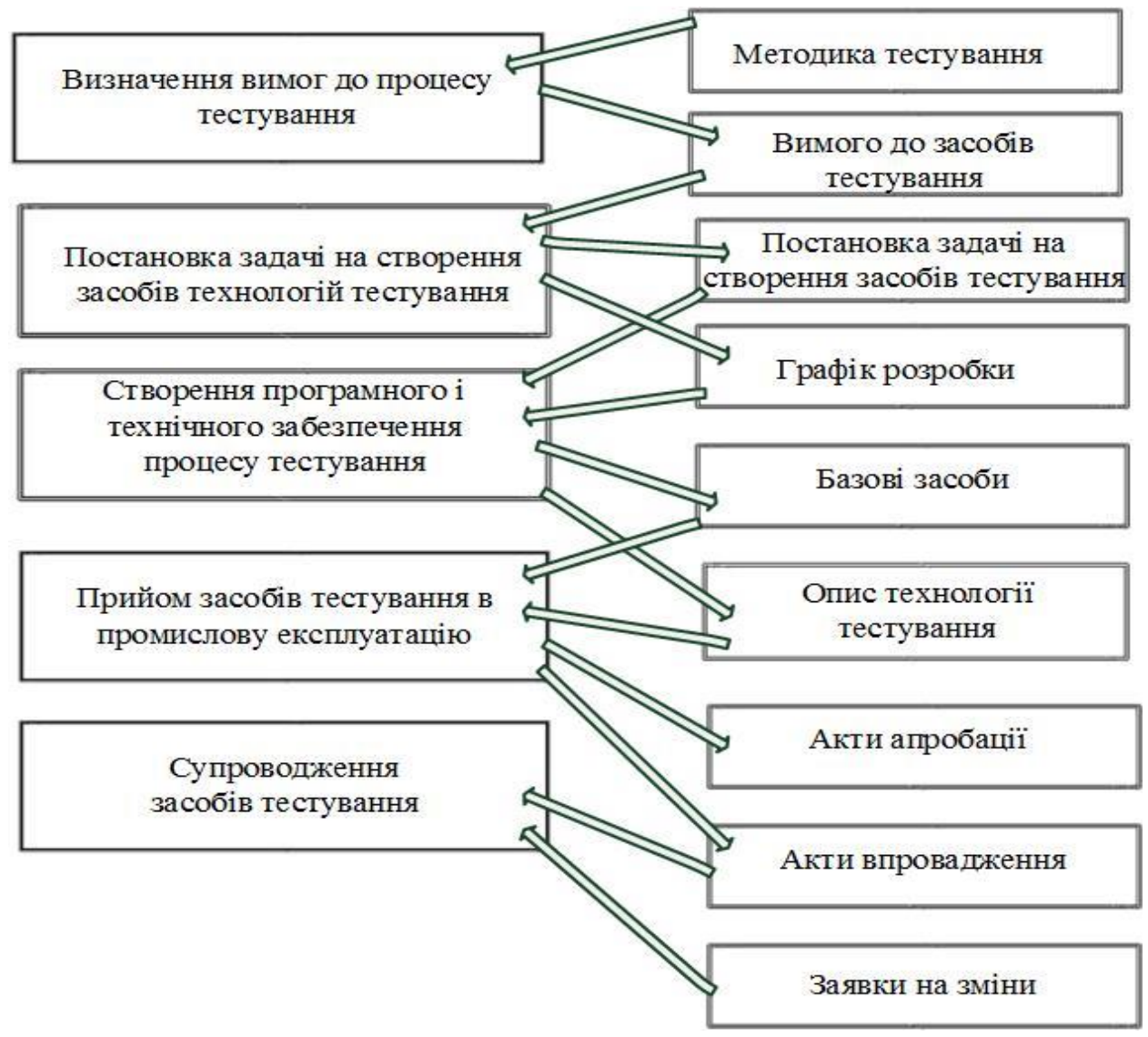

Рис. 1. Граф взасмодії в процесі підготовки засобів тестування

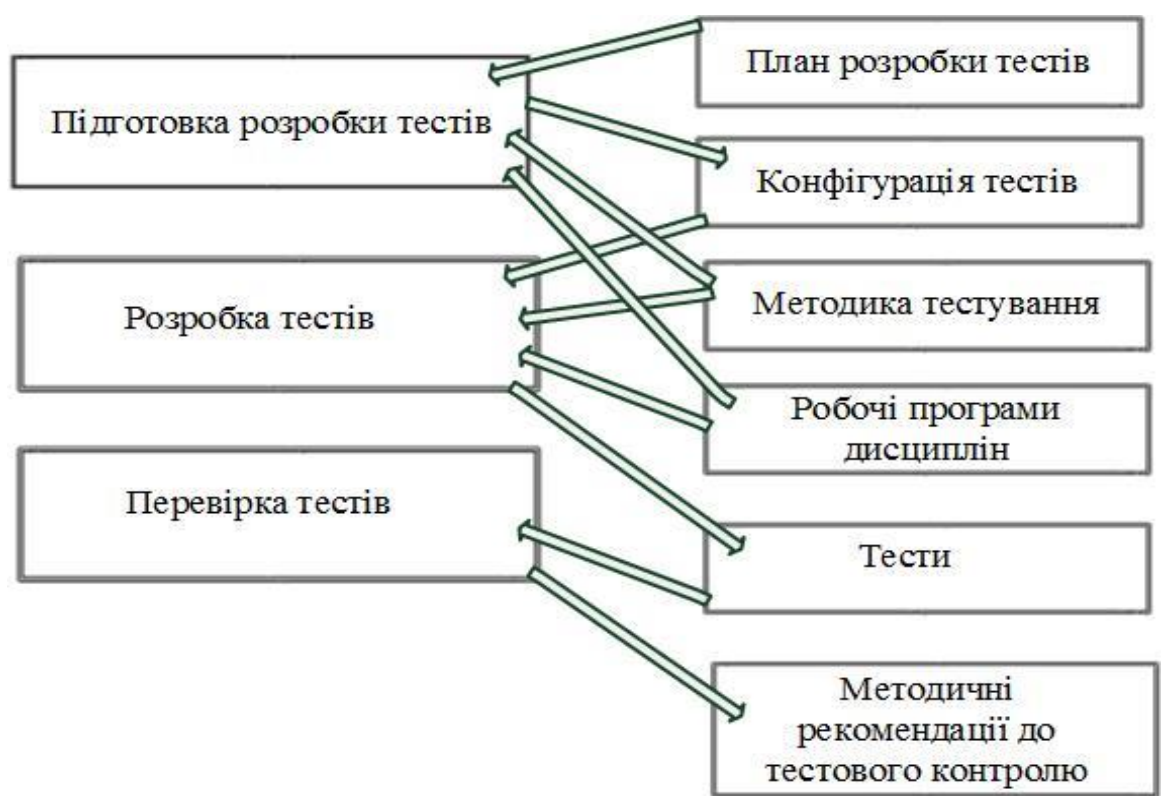

Рис. 2. Граф взаємодії в процесі розробки тестів 
Висновок. Запропоновано метод управління формуванням та реалізацією підготовки і проведення тестового контролю знань при дистанційному навчанні студентів на основі сучасних інструментальних програмних середовищ. Основними критеріями вибору засобів тестування були: відкритість, безкоштовність, простота використання. Таким критеріям відповідає безкоштовна веб-платформа дистанційного навчання Moodle.

Визначено специфіку управління навчальними і тестовими інформаційними технологіями. Виділення в технології навчання компонента управління дає змогу представити реалізацію технології дистанційного навчання i тестування на рівнях управління і навчання як сукупність методів і засобів взаємодоповнюючого перетворення інформації, що використовується як для навчання, так і для управління вищим навчальним закладом. Це забезпечить якісний процес взаємодії в середовищі знань суб'єктів навчання та дозволить ефективно автоматизувати процес підготовки фахівців у вищих навчальних закладах України.

\section{Список літератури}

1. Биков В. Ю. Структура актуальних напрямків (тематики) досліджень проблем дистанційної професійної освіти. Вісник Академії дистаниійної освіти. 2003. № 1. C. 22-26.

2. Биков В. Ю., К Кухаренко В. М., Сиротенко Н. Г., Рибалко О. В., Богачков Ю. М. Технології розробки дистанційного курсу: навч. посіб. Київ: Міленіум, 2008. 324 с.

3. Михальченко М. Освіта і наука: пошуки нових парадигм модернізації. Вища освіта Украӥни. 2001. № 2. С. 14-23.

4. Олійник В. В. Теоретичні та методичні засади розвитку системи підвищення кваліфікації працівників профтехосвіти на основі дистанційних технологій: навч. посіб. НАПН України, Ун-т менедж. освіти. Київ, 2010. 268 с.

5. Жулкевсъка В. Теоретико-методологічні основи дистанційного навчання. Педагогіка і психологія професійної освіти. 2002. № 1. C. 52-59.

6. Жевакіна Н. В. Ефективність дистанційних технологій навчання. Освіта Донбасу. 2004. № 2. C. 73-78.
7. Кухаренко В. М., Березенська С. М., Бугайчук К. Л., ник Т. О., Рибалко О. В., Сиротенко Н. Г., Столяревська А. Л. Теорія та практика змішаного навчання: монографія. Харків: Міськдрук, НТУ «ХПІ», 2016. 284 с.

8. Стефаненко П. Теоретичні i методичні засади дистанційного навчання у вищій школі: дис. д-ра пед. наук: 13.00.04. Київ, 2002. $470 \mathrm{c}$.

9. Вишнівський В. В., Гнніденко М. П., Гайдур Г. І., Ільїн О. О. Організація дистанційного навчання. Створення електронних навчальних курсів та електронних тестів: навч. посіб. Київ: ДУТ, 2014. 140 с.

10. Анисимов А. М. Работа в системе дистанционного обучения Moodle: учеб. пособие. 2-е изд., испр. и доп. Харьков: ХНАГХ, 2009. $292 \mathrm{c}$.

11. Лізунов П. П., Т Тесля Ю. М., Білошицький О. А., Щербина А. О., Білошицька С. В., Мисник Л. Д. Організаційні аспекти системи тестування для проміжного $\mathrm{i}$ підсумкового контролю знань студентів. Інформаційні технології в освіті: зб. наук. np. Вип. 4. Херсон: Вид-во ХДУ, 2009. $288 \mathrm{c}$.

\section{References}

12. Bykov, V. Yu. (2003) Structure of actual directions (topics) of research of problems of distance professional education. Visnyk Akademii dystantsiinoi osvity, No. 1, pp. 22 26 [in Ukrainian].

13. Bykov, V. Yu., Kuharenko, V. M., Syrotenko, N. H., Rybalko, O. V. and Bohachkov, Yu. M. (2008) Technologies of development of remote course. Kyiv: Milenium, 324 p. [in Ukrainian].

14. Mychalchenko, M. (2001) Education and science: in search of a new modernization paradigm. Vyshcha osvita Ukrainy, No. 2, pp. 14-23 [in Ukrainian].

15. Oliynyk, V. V. (2010) Theoretical and methodological bases of the development of the system of professional skills of professional education workers on the basis of remote technologies. Ukrainian National Pedagogical Academy, Economy Studies University, Kyiv, 268 p. [in Ukrainian].

16. Zhulkevska, V. (2002) Remote education theoretical and methodological bases. 
Pedahohika i psykholohiia profesiinoi osvity, No. 1, pp. 52-59 [in Ukrainian].

17. Zhevakina, N. V. (2004) Effectiveness of remote educational technologies. Osvita Donbasu, No. 2, pp. 73-78 [in Ukrainian].

18. Kuharenko, V. M., Berezenska, S. M., Buhaychuk, K. L., Oliynyk, N. Yu., Oliynyk, T. O., Rybalko, O. V., Syroten-ko, N. H. and Stolyarevska, A. L. (2016) Theory and practice of combined education: monograph. Kharkiv: Miskdruk, NTU «KhPI», 284 p. [in Ukrainian].

19. Stephanenko, P. (2002) Theoretical and methodological bases of remote high education: diss. for D.Sc.: 13.00.04, Kyiv, 470 p. [in Ukrainian].
20. Vyshnivsky, V. V., Hnidenko, M. P., Haydur, H. I. and Ilyin, O. O. (2014) Organization of distance learning. Creating elearning courses and electronic tests. Kyiv: DUT, 140 p. [in Ukrainian].

21. Anisimov, A. M. (2009) Work in the Moodle distance learning system. 2nd ed.. Kharkiv: KhNAHKh, 292 p. [in Russian].

22. Lizunov, P. P., Teslya, Yu. M., Byloshytsky, O. A., Shcherbyna, A. O., Byloshchytska, S. V. and Mysnyk, L. D. (2009) Organizational aspects of the testing system for intermediate and final student knowledge control. Informatsiini tekhnolohii $v$ osviti, vol. 4, Kherson, Vyd-vo KhDU, 288 p. [in Ukrainian].

L. D. Mysnyk, Ph.D., associate professor

Cherkasy State Technological University

Shevchenko blvd, 460, Cherkasy, 18006, Ukraine

e-mail: 1.mysnyk@chdtu.edu.ua

\section{MANAGEMENT BY FORMATION AND IMPLEMENTION OF TRAINING AND KNOWLEDGE CONTROL AT DISTANCE LEARNING OF STUDENTS}

The article is devoted to the search for new forms and methods of teaching, to the improvement of test technologies in order to meet the European requirements and the ability to manage the formation and implementation of training and management of knowledge in distance learning. The method of test technologies management, which is realized through the functions of organization, planning and monitoring, is presented. The proposed method is based on the reflection of management processes in bipartite graphs with a further elaboration of the model of implementation of actions by following the activity between static and dynamic elements of these technologies.

Key words: distance learning technologies, methods of management by information technologies, test technologies and knowledge control.

Стаття надійшла 05.02.2018.

Рецензенти: В.І. Осипенко, д.т.н., професор,

С. В. Поздєєв, д.т.н., професор. 